\title{
Substituição da Silagem de Milho pela Silagem do Bagaço de Laranja na Alimentação de Vacas Leiteiras. Consumo, Produção e Qualidade do Leite ${ }^{1}$
}

\author{
Luís Carlos Vinhas Ítavo ${ }^{2}$, Geraldo Tadeu dos Santos ${ }^{3 *}$, Clóves Cabreira Jobim³, \\ Tadeu Vinhas Voltolini ${ }^{4}$, Camila Celeste Brandão Ferreira ${ }^{5}$
}

\begin{abstract}
RESUMO - Estudaram-se os efeitos da substituição da silagem de milho pela silagem de bagaço de laranja sobre o consumo de nutrientes, a produção e a qualidade do leite de vacas da raça holandesa, num experimento em quadrado latino 4 x 4, com quatro níveis de substituição $(0,25,50$ ou $75 \%$ MS $)$ da silagem de milho pela silagem de bagaço de laranja, com base na matéria seca, mantendo-se a relação volumoso:concentrado de 50:50. Os níveis de substituição não influenciarram as porcentagens de gordura e proteína do leite, porém o comportamento do consumo de nutrientes e produção de leite se deu de forma quadrática, em função do nível de substituição. Os resultados sugerem que a silagem de bagaço de laranja pode substituir a silagem de milho para vacas em lactação.
\end{abstract}

Palavras-chave: bagaço de laranja, consumo, níveis de substituição, subprodutos

\section{Replacement of Corn Silage by Orange Peel Silage in the Feeding of Dairy Cows. Intake, Milk Production and Composition}

\begin{abstract}
The effects of the replacement of corn silage by orange peel silage were studied on the intake of nutrients, production and quality of the milk of Holstein dairy cows. A 4 x 4 Latin square design with four replacement levels (0, 25, 50 or 75\% DM) of corn silage by orange peel with forage to concentrate ratio of 50:50 were used. The replacement levels did not affect the percentage of milk fat and milk protein, however the nutrient intake and milk production showed a quadratic behavior in function of the replacement level of corn silage by orange peel silage. The results suggest that the silage of orange peel can substitute the corn silage for lactating dairy cows.
\end{abstract}

Key Words: orange peel, byproducts, intake, replacement levels

\section{Introdução}

A necessidade de fornecer silagem como fonte de fibra aos ruminantes está associada à baixa produção de forrageiras nas épocas de escassez de chuvas. Desse modo, a silagem de milho ou sorgo é freqüentemente utilizada como um dos principais alimentos de inverno (RUIZ e MUNARI, 1992).

Silagens de boa qualidade podem ser produzidas com materiais in natura, por meio da própria fermentação e condições adequadas de conservação. Segundo ASHBELL (1987), nas fazendas de Israel, dadas as condições econômicas, três alimentos têm potencial para preencher esses requisitos: milho, trigo e bagaço de laranja. WEINBERG (1992) citou que, entre os diferentes subprodutos existentes, o bagaço de laranja poderia ser conservado na forma de silagem.

A indústria de suco de laranja produz como subproduto o bagaço de laranja, que compreende cerca de $42 \%$ do total da fruta. Seu valor para a alimentação de ruminantes é semelhante aos grãos, pois possui elevado valor de digestibilidade (ASHBELL, 1992; VAN SOEST, 1994; e ÍTAVO et al., 1998), todavia, a composição química, palatabilidade e valor nutritivo sofrem influência do processo de desidratação da laranja, da variedade da fruta e do tipo de operação pelo qual o resíduo é obtido (BRANCO et al., 1994)

Devido ao elevado custo de secagem, há interesse das empresas em desenvolver mercados para o bagaço cítrico úmido. Este interesse é maior, particularmente, para aquelas pequenas esmagadoras de laranja que produzem suco natural engarrafado, ou para grandes empresas que não pretendem, em suas fábricas futuras, despender o alto investimento necessário à secagem do bagaço de laranja, pois este pode chegar a 50\% do investimento total da fábrica (CARVALHO, 1995).

A produção de leite tem sido um dos aspectos

\footnotetext{
${ }^{1}$ Parte da Dissertação de Mestrado apresentada pelo primeiro autor a Universidade Estadual de Maringá

2 Zootecnista, M.Sc., Professor do Curso de Zootecnia da Universidade Católica Dom Bosco - UCDB, Campo Grande - MS . E.mail: itavo@ucdb.br 3 Professor do DZO/CCA - UEM, Av. Colombo, 5790. CEP 87.020-900, Maringá, PR. * Bolsista do CNPq.

${ }^{4}$ Aluno do curso de Zootecnia/UEM - Maringá, PR

${ }^{5}$ Aluna do Curso de Zootecnia/UFV - Viçosa, MG.
} 
mais avaliados quanto à introdução do bagaço de laranja desidratado em dietas de ruminantes, no qual o grande espaço a ser ocupado pelo produto está na substituição dos grãos de cereais. Estima-se que, nos Estados Unidos, 90\% do bagaço cítrico utilizado são consumidos por vacas em lactação, mostrando-se um alimento de alto potencial (CARVALHO, 1995).

SANTOS et al. (1993) apresentaram especificações de rações para um programa de alimentação de rebanho leiteiro em quatro grupos. Para a fase inicial (0 a 70 dias), a ração total misturada (RTM) deveria ter 16 a $18 \%$ de PB, com 40 a $42 \%$ de proteína não-degradável no rúmen e, ainda, 25 a $29 \%$ de FDN e 17 a $22 \%$ de FDA.

Segundo PERES (1997), estudos são necessários para se avaliar o subproduto da indústria de sucos cítricos, pois estes possuem padrão de fermentação ruminal bastante distinto, podendo apresentar resultados positivos para vacas em lactação. $\mathrm{O}$ bagaço de laranja é particularmente rico em pectina, que tem rápida e alta degradação, porém não acidifica com intensidade o ambiente ruminal, em virtude de o produto final de sua degradação ser o ácido acético (VAN SOEST, 1994).

A regulação da ingestão envolve sinais de fome e saciedade que operam por meio de vários mecanismos hormonais e neurais para controlar a ingestão voluntária. Quando dietas de alta qualidade são fornecidas, o animal se alimenta para satisfazer sua demanda de energia, e a ingestão é limitada pelo potencial genético do animal em utilizar a energia absorvida. Entretanto, quando dietas de baixa qualidade são fornecidas, o animal consome o alimento no nível que corresponde à capacidade do trato gastrintestinal. $\mathrm{O}$ papel dominante da regulação fisiológica e limitação física na ingestão é modificado por estímulos relacionados à palatabilidade, à doença e ao manejo alimentar. Dessa forma, a ingestão é afetada por características do animal, do alimento e da forma de alimentação (MERTENS, 1994).

Objetivou-se com o presente experimento determinar os efeitos do nível de substituição da silagem de milho pela silagem de bagaço de laranja em vacas em lactação sobre o consumo de nutrientes, a produção e a qualidade do leite de vacas da raça Holandesa.

\section{Material e Métodos}

O trabalho foi conduzido na Fazenda Experimental de Iguatemi, PR, no Laboratório de Análises de Alimentos e Nutrição Animal e no Laboratório de
Metabolismo Animal do Departamento deZootecnia da Universidade Estadual de Maringá, em Maringá, PR.

Foram utilizadas quatro vacas da raça Holandês, multíparas, em lactação, com $111 \pm 22$ dias de lactação. Os tratamentos constituíram-se de quatro níveis de substituição da silagem de milho pela silagem de bagaço de laranja, sendo 0, 25, 50 e 75\% da MS.

Foram ensiladas $50 \mathrm{t}$ de bagaço de laranja, proveniente da COCAMAR-CITRUS S/A de Paranavaí, $\mathrm{PR}$, em dois silos do tipo trincheira, sem revestimento, sendo o primeiro aberto com 140 dias de ensilagem. A silagem de milho utilizada foi confeccionada pela Fazenda Experimental de Iguatemi, PR.

A ração total misturada (RTM) foi fornecida com a proposta de se fornecer dieta isoprotéica e isoenergética para os grupos de vacas, em uma relação volumoso:concentrado de 50:50.

$\mathrm{O}$ experimento seguiu esquema em quadrado Latino (4 x 4), com quatro períodos de 21 dias cada. Após 14 dias de adaptação, foram medidos os valores de consumo de nutrientes, produção leiteira e qualidade do leite de cada vaca, por um período de sete dias consecutivos.

Foram determinados nas silagens e nas rações os valores de MS, PB, EE e EB, segundo técnica descrita por SILVA (1990), e FDN e FDA, segundo GOERING e VAN SOEST (1970). Mensurou-se a gordura do leite, pelo método do butirômetro de Gerber, e da proteína, segundo técnica descrita por SILVA (1990).

As análises estatísticas foram realizadas por intermédio do Sistema de Análises Estatísticas e Genéticas - SAEG (UNIVERSIDADE FEDERAL DE VIÇOSA - UFV, 1997). As médias foram comparadas pelo teste Tukey, a 5\% de significância. Para as equações de regressão, seguiu-se o modelo matricial:

$$
\mathrm{Y}=\mathrm{X} \beta+\varepsilon
$$

em que $\mathrm{Y}$ é o vetor dos valores observados; $\mathrm{X}$, a matriz correspondente aos valores das variáveis independentes; $\beta$, o vetor de parâmetros desconhecidos; e $\varepsilon$, o vetor de erros aleatórios ( $\mathrm{N} \times 1)$, em que $\mathrm{e} \sim \mathrm{N}\left(\mathrm{f}, \mathrm{I} \sigma^{2}\right)$;

\section{Resultados e Discussão}

As composições bromatológicas das silagens, do milho e do bagaço de laranja encontram-se na Tabela 1. Os valores referentes à silagem do bagaço de laranja concordam com ASHBELL (1987) e WEINBERG (1992), os quais afirmaram que o bagaço de laranja poderia produzir silagem de boa qualidade, por interméddio da própria fermentação e das condições 
1500 Rev. bras. zootec.

adequadas de conservação.

A composição das rações, para cada nível de substituição, está apresentada na Tabela 2. Houve diferença no teor de MS das rações somente no nível zero de substituição, que apresentou o maior conteúdo de MS $(\mathrm{P}<0,05)$. Visto que a proposta do experimento foi fornecer rações isoprotéicas e isoenergéticas (Tabela 2), não houve diferença quanto aos teores de proteína bruta (PB) e energia bruta (EB) das rações.

Apesar de os valores de FDN não terem diferido significativamente $(\mathrm{P}>0,05)$, pode-se observar que a ração com silagem de milho exclusivamente apresentou praticamente nove pontos percentuais acima do valor da ração com $75 \%$ de substituição, provavelmente devido ao elevado coeficiente de variação encontrado para os valores de FDN das dietas. A ração com o nível de $75 \%$ de substituição mostrou o menor valor para o teor de FDA $(\mathrm{P}<0,05)$.

A silagem de bagaço de laranja praticamente atende às exigências citadas por SANTOS et al. (1993), com exceção da PB (Tabela 1), que atingiu praticamente a metade do valor, para vacas durante a fase inicial da lactação, porém, na segunda fase (71 a 140 dias de lactação), a RTM deveria ter entre 13 a $15 \%$ de $\mathrm{PB}$, sendo $38 \%$ dessa proteína não-degradada no rúmen; 31 e $36 \%$ de FDN; e 28 a $34 \%$ de FDA. Assim, as rações preenchem praticamente todas as exigências nutricionais. A silagem de bagaço de laranja, devido à sua composição, seria o alimento certo para atender às exigências citadas por SANTOS et al. (1993), desde que se corrigisse o teor protéico da ração, durante o início da lactação.

A silagem de bagaço de laranja proporcionou maiores quantidades de MS ingerida. O consumo de

Tabela 1 - Composição bromatológica da silagem de milho e da silagem de bagaço de laranja (\%MS)

Table 1 - Chemical composition of corn silage and orange peel silage (\% DM)

\begin{tabular}{lccccc}
\hline Silagem & MS & PB & FDN & FDA & EE \\
Silage & $D M$ & $C P$ & $N D F$ & $A D F$ & $E E$ \\
\hline $\begin{array}{l}\text { Milho } \\
\text { Corn }\end{array}$ & 31,00 & 8,31 & 45,13 & 20,09 & 1,12 \\
$\begin{array}{l}\text { Bagaço de } \\
\text { laranja }\end{array}$ & 12,00 & 9,09 & 30,16 & 21,68 & 2,04 \\
Orange peel & & & & & \\
\hline
\end{tabular}

$\overline{\mathrm{MS}}=$ matéria seca; $\mathrm{PB}$ = proteína bruta; FDN = fibra em detergente neutro; FDA = fibra em detergente ácido; $E E$ = extrato etéreo.

$D M=$ dry matter $; C P=$ crude protein,$N D F=$ neutral detergent fiber $; A D F=$ acid detergent fiber, $E E=$ ether extract.
Tabela 2 - Composição bromatológica da ração total misturada (RTM), em função do nível de substituição

Table 2 - Chemical composition of mixed total diet (TRM), in function of the replacement level of corn silage by orange peel silage

\begin{tabular}{lccccc}
\hline $\begin{array}{l}\text { Tratamentos } \\
\text { Treatment }\end{array}$ & $\begin{array}{c}\text { MS } \\
(\%)\end{array}$ & $\begin{array}{c}\text { PB } \\
(\%)\end{array}$ & $\begin{array}{c}\text { FDN } \\
(\%)\end{array}$ & $\begin{array}{c}\text { FDA } \\
(\%)\end{array}$ & $\begin{array}{c}\mathrm{EE} \\
(\mathrm{Cal} / \mathrm{g})\end{array}$ \\
\hline 0 & $D M$ & $C P$ & $N D F$ & $A D F$ & $E E$ \\
\hline 25 & $35,79^{\mathrm{a}}$ & $14,49^{\mathrm{a}}$ & $47,45^{\mathrm{a}}$ & $23,93^{\mathrm{a}}$ & $4043,21^{\mathrm{a}}$ \\
50 & $27,11^{\mathrm{b}}$ & $14,82^{\mathrm{a}}$ & $46,10^{\mathrm{a}}$ & $21,99^{\mathrm{ab}}$ & $4025,71^{\mathrm{a}}$ \\
75 & $26,26^{\mathrm{b}}$ & $16,23^{\mathrm{a}}$ & $42,23^{\mathrm{a}}$ & $19,74^{\mathrm{ab}}$ & $4021,43^{\mathrm{a}}$ \\
& $23,28^{\mathrm{b}}$ & $17,03^{\mathrm{a}}$ & $38,71^{\mathrm{a}}$ & $17,61^{\mathrm{b}}$ & $4012,40^{\mathrm{a}}$ \\
$\mathrm{CV}$ & 11,135 & 30,206 & 42,405 & 13,582 & 1,859 \\
\hline
\end{tabular}

Médias seguidas por letras minúsculas diferentes, na mesma coluna, diferem $(P<0,05)$ pelo teste Tukey.

$\mathrm{MS}=$ matéria seca; $\mathrm{PB}=$ proteína bruta; $\mathrm{FDN}=$ fibra em detergente neutro; FDA = fibra em detergente ácido; EB = energia bruta $(\mathrm{Cal} / \mathrm{g})$;

$\mathrm{CV}=$ Coeficiente de variação.

Means, within columns, with different letter differ $(P<.05)$ by Tukey test.

$D M=$ drymatter $; C P=$ crude protein, $N D F=$ neutral detergent fiber $; A D F=$ acid detergent fiber, GE = gross energy $(\mathrm{Cal} / \mathrm{g})$;

$C V=$ Coefficient of variation.

MS apresentou comportamento quadrático (Tabela 3), com aumento no consumo de MS, a partir do nível de $25 \%$. O nível de $25 \%$ de substituição foi o que atingiu o valor mínimo de consumo de MS, porém há de se destacar que, a partir desse ponto, o consumo de MS aumentou até atingir o ponto máximo, dentro da faixa de substituição ( 0 a $75 \%)$. Tal fato sugere que o controle da ingestão ocorreu de forma metabólica, (MERTENS, 1994), devido ao baixo valor de FDA da silagem de bagaço de laranja, que está diretamente ligada ao efeito de enchimento, além de seu alto potencial de degradação, que proporcionaria elevada produção de ácidos graxos voláteis.

A ingestão de matéria seca, em relação ao peso do animal vivo (PV), não diferiu entre as substituições, e os valores variaram de 2,5 a 2,0\% PV. SANTOS et al. (1993) preconizaram como 2,5\% PV a IMS para as diferentes fases do ciclo produtivo da vaca leiteira, para fins de manejo, com valores acima de 3\% após os 70 dias de lactação, quando o animal praticamente atinge o pico de ingestão de MS. Todavia, estes valores se referem a vacas de alta produção, isto é, acima de $25 \mathrm{~kg}$ de leite por dia, sendo que a produção média das vacas deste experimento foi $21 \mathrm{~kg}$, o que justificaria o menor consumo.

Analisando os valores referentes ao consumo de 
ÍTAVO et al.

Tabela 3 - Equações de regressão ajustadas para o consumo dos nutrientes da dieta, por vacas leiteiras, em função do nível de substituição (S), em porcentagem, da MS da silagem de milho pela MS da silagem de bagaço de laranja

Table 3 - Fitted regression equations for diet's nutrients intake by dairy cows in function of replacement level of (S), in percentage of corn silage DM by orange peel silage DM

\begin{tabular}{lcc}
\hline $\begin{array}{l}\text { Consumo (kg/dia) } \\
\text { Intake }(\text { kg/day) }\end{array}$ & \multicolumn{1}{c}{$\begin{array}{c}\text { Regressão } \\
\text { Regression }\end{array}$} & $\mathrm{R}^{2}$ \\
\hline $\mathrm{MS}(D M)$ & $\mathrm{Y}=10,37890-0,02151793 * \mathrm{~S}+0,0007782623 * \mathrm{~S}^{2}$ & 0,99 \\
$\mathrm{~PB}(C P)$ & $\mathrm{Y}=1,6008815+0,0007114198 * \mathrm{~S}+0,0001361566 * \mathrm{~S}^{2}$ & 0,97 \\
$\mathrm{FDN}(N D F)$ & $\mathrm{Y}=4,596279-0,02292342 * \mathrm{~S}+0,0002638344 * \mathrm{~S}^{2}$ & 0,99 \\
$\mathrm{FDA}(A D F)$ & $\mathrm{Y}=2,164315-0,01404343 * \mathrm{~S}+0,000166891 * \mathrm{~S}^{2}$ & 0,99 \\
$\mathrm{~EB}(C E)$ & $\mathrm{Y}=41751,67-91,07764 * \mathrm{~S}+3,178750 * \mathrm{~S}^{2}$ & 0,99 \\
\hline
\end{tabular}

$\mathrm{R}^{2}=$ coeficiente de determinação ( $R^{2}=$ coefficient of determination).

MS, pode-se constatar que houve aumento para os níveis crescentes de substituição após $25 \%$, sugerindo que a silagem de bagaço de laranja pode ser incluída nas dietas de vacas leiteiras, corroborando, portanto, a afirmação de LUCCI et al. (1975) de que o milho desintegrado pode ser substituído totalmente pelo bagaço de laranja desidratado, em misturas concentradas para vacas em lactação. Afirmaram também que misturas concentradas com até $67 \%$ de bagaço seco de laranja podem ser utilizadas, sem que haja redução no consumo ou outros efeitos indesejáveis.

Pode-se observar que não houve diferença $(\mathrm{P}>0,05)$ entre os níveis para a proteína e gordura do leite (Tabela 4), sugerindo que a silagem de bagaço de laranja não alterou a qualidade e a porcentagem de gordura e proteína do leite, mostrando ser um substituto efetivo da MS da silagem do milho. Quanto à produção de leite, observou-se comportamento quadrático significativo da produção para níveis crescentes de silagem de bagaço de laranja na ração total
(Tabela 4). Substituindo-se os valores para a porcentagem de substituição, verificou-se redução na produção, com o aumento do nível de silagem de bagaço de laranja, todavia, em experimentos com produção leiteira, os resultados tendem a diminuir naturalmente, pois o fenômeno acompanha uma curva que atinge seu pico por volta dos 45 aos 60 dias após o parto. Estes resultados também foram encontrados por FEGEROS et al. (1995), que trabalharam com ovelhas em lactação e não verificaram diferenças significativas na produção e composição do leite, quando substituíram o milho ou a cevada por bagaço cítrico desidratado.

BELIBASAKIS e TSIRGOGIANNI (1996), estudando os efeitos do bagaço de laranja desidratado e peletizado na produção de leite, além da composição e dos componentes sangüíneos, em vacas em lactação, alimentadas duas vezes ao dia, não observaram diferença na ingestão de MS, PB e energia metabolizável, produção de leite, conteúdo de prote-

Tabela 4 - Equações de regressão ajustadas para a produção de leite, em função do nível de substituição (S), em porcentagem, da MS da silagem de milho pela MS da silagem de bagaço de laranja.

Table 4 - Fitted regression equations for milk yield, in function of replacement levels (S), in percentage, of corn silage DM by orange peel silage DM

\begin{tabular}{|c|c|c|}
\hline $\begin{array}{l}\text { Produção } \\
\text { Yield }\end{array}$ & $\begin{array}{l}\text { Regressão } \\
\text { Regression }\end{array}$ & $\mathrm{R}^{2}$ \\
\hline $\begin{array}{l}\text { Leite (kg/dia) } \\
\text { Milk (kg/day) }\end{array}$ & $Y=21,5943-0,0100801 * S-0,000327999 * S^{2}$ & 0,99 \\
\hline $\begin{array}{l}\text { Leite corrigido } 4 \%(\mathrm{~kg} / \mathrm{dia}) \\
4 \% \text { corrected mild (kg/day) }\end{array}$ & $\mathrm{Y}=19,1456+0,00320007 * \mathrm{~S}-0,000358212 * \mathrm{~S}^{2}$ & 0,99 \\
\hline $\begin{array}{l}\text { Proteína }(\%) \\
\text { Protein }(\%)\end{array}$ & $\mathrm{Y}=2,943941$ & $\mathrm{NS}^{\#}$ \\
\hline $\begin{array}{l}\text { Gordura }(\%) \\
\text { Fat }(\%)\end{array}$ & $\mathrm{Y}=3,619375$ & $\mathrm{NS}^{\#}$ \\
\hline
\end{tabular}


1502 Rev. bras. zootec.

ína e lactose do leite. Os autores concluíram que a inclusão de $20 \%$ do bagaço desidratado e peletizado na ração total, o que corresponderia ao nível de $25 \%$ de substituição da MS da silagem de milho pela MS da silagem de bagaço de laranja, aumentou significativamente o conteúdo de gordura do leite, produção e concentração de colesterol sangüíneo. Esses resultados foram diferentes dos obtidos no presente estudo, para a porcentagem de gordura do leite das vacas alimentadas com a silagem de bagaço de laranja, os quais permaneceram constantes para os níveis de substituição da MS da silagem de milho pela MS da silagem de bagaço de laranja.

A porcentagem de gordura do leite das rações não sofreu efeito dos níveis de substituição $(\mathrm{P}>0,05)$, sendo em média 3,6\% (Tabela 4). À medida que se aumentou a porcentagem de silagem de bagaço de laranja na ração, houve aumento de carboidratos não-estruturais, o que poderia ter promovido diminuição da porcentagem de gordura do leite, em razão de o produto final da fermentação desses carboidratos serem os ácidos propiônico e/ou ácido láctico. Não obstante, o bagaço de laranja é um alimento rico em pectina, fazendo com que isso não aconteça. A fermentação da pectina é peculiar, gerando grande quantidade de energia por unidade de tempo, como ocorre com o amido e os açúcares, porém a fermentação é acética, que pode ser confirmado por ÍTAVO et al. (1999), os quais observaram produção de acetato por volta de $85 \%$ do total de AGV. Além disso, a pectina possui elevada capacidade de evitar a queda do $\mathrm{pH}$ ruminal, por intermédio de um mecanismo próprio de tamponamento (VAN SOEST, 1994).

Os níveis mais elevados de substituição da silagem de milho pela silagem de bagaço de laranja, teoricamente, fornecem mais carboidratos nãoestruturais para os animais. COOMER et al. (1993), avaliando os carboidratos não-estruturais e suas respostas na lactação e componentes do leite, concluíram que altas concentrações de fibra proveniente de subprodutos com rápida degradação, incluídos na dieta, podem elevar o concentrado da ração, sem subseqüente redução no conteúdo de gordura do leite. Esta prática poderia aumentar a ingestão de energia durante o início da lactação, podendo aliviar a necessidade de suplementação de gordura e posterior diminuição na porcentagem de proteína do leite.

\section{Conclusões}

A substituição da MS da silagem de milho pela MS da silagem de bagaço de laranja é uma prática de manejo alternativa, dependendo da disponibilidade de milho, do subproduto e dos custos envolvidos no sistema de produção. Apesar dos resultados promissores, ainda são necessárias mais pesquisas sobre a utilização da silagem de bagaço de laranja como de substituição da silagem de milho para alimentação de vacas leiteiras.

\section{Referências Bibliográficas}

ASHBELL, G. Conservation of citrus peel by ensiling for ruminant feed In: SIMPÓSIO UTILIZAÇÃO DE SUBPRODUTOS AGRO-INDUSTRIAIS E RESÍDUOS DE COLHEITA NA ALIMENTAÇÃO DE RUMINANTES, 1992, São Carlos, SP. Anais...São Carlos: EMBRAPA/ UEPAE, 1992. p.189-190.

ASHBELL, G. The potential for high quality silage production from homegrown forage and by-products in Israel. In: AGRICULTURAL RESEARCH ORGANIZATION, 1987, Bet Dagan, Israel. Proceedings... Bet Dagan: The Volcani Center, 1987. p.153-160.

BELIBASAKIS, N.G., TSIRGOGIANNI, D. 1996. Effects of dried citrus pulp on milk yield, milk composition and blood components of dairy cows. Anim. Feed Sci. Techn., 60:87-92.

BRANCO, A.F., ZEOULA, L.M., PRADO, I.N. et al. 1994. Valor nutritivo da polpa de citrus in natura para ruminantes. Rev.Unimar, 16(1):37-48.

CARVALHO, M.P. Citros. In: SIMPÓSIO SOBRE NUTRIÇÃO DE BOVINOS, 1995, Piracicaba. Anais...Piracicaba: FEALQ.1995. p.171-214.

COOMER, J.C., AMOS, H.E., WILLIAMS, C.C. et al. 1993. Response of early lactation cows to fat supplementation in diets with different nonstructural carbohydrate concentration. J. Dairy Sci., 76(12):3747-3754.

FEGEROS, K., ZERVAS, G., STAMOULI, S. et al. 1995. Nutritive value of dried citrus pulp and its effect on milk yield and milk composition of lactating ewes. J. Dairy Sci., 78(5):1116-1121.

GOERING, H.K., VAN SOEST, P.J. 1970. Forage fiber analysis. Handbook n.379. Washington, D.C.: Agricultural Research Service, USDA. p. 210-212.

ÍTAVO, L.C.V., SANTOS, G.T., JOBIM, C.C. et al. Consumo e digestibilidade aparente da silagem de bagaço de laranja. In: REUNIÃO ANUAL DA SOCIEDADE BRASILEIRA DE ZOOTECNIA, 35, 1998, Botucatu. Anais... Botucatu, SP, 1998, p.388-390.

ÍTAVO, L.C.V., SANTOS, G.T., JOBIM, C.C. et al. Consumo e parâmetros de fermentação ruminal de vacas fistuladas alimentadas com silagem de bagaço de laranja em níveis de substituição à silagem de milho. In: REUNIÃO ANUAL DA SOCIEDADE BRASILEIRA DE ZOOTECNIA, 36, 1999, Porto Alegre. Anais...Porto Alegre, RS, 1999, p.266.

LUCCI, C.S., VELLOSO, L., MASOTTI, N. et al. 1975. Polpa seca de laranja versus milho desintegrado em misturas con- 
centradas para vacas em lactação. Rev. Fac. Med. Vet. Zootec., 12:163-168.

MERTENS, D.R. Regulation of forage intake. In: NATIONAL CONFERENCE ON FORAGE QUALITY. EVALUATION AND UTILIZATION, 1994. University of Nebraska. Proceedings... Lincoln. 1994. p.450-493.

PERES, J.R. Avaliação da polpa de citrus seca e peletizada como aditivo na ensilagem do capim-elefante (Pennisetum purpureum, Schum). Piracicaba, SP: ESALQ-USP, 1997. 71p. Dissertação (Mestrado em Agronomia) - Escola Superior de Agricultura Luiz de Queiroz - Universidade de São Paulo, 1997.

RUIZ, R.L., MUNARI, D.P. 1992. Microbiologia da silagem In: RUIZ, R.L. (Ed.) Microbiologia zootécnica. São Paulo: Ed. Roca. p.97-122.

SANTOS, G.T., PRADO, I.N., BRANCO, A.F. et al. 1993 Aspectos do manejo do gado leiteiro especializado. Apontamentos. Maringá: UEM. 23p.
SILVA, D.J. 1990. Análise de alimentos (Métodos químicos e biológicos). Viçosa: UFV, Imprensa Universitária. 165p.

UNIVERSIDADE FEDERAL DE VIÇOSA - UFV. 1997. SAEG Sistema de análises estatísticas e genéticas. Versão 7.1. Viçosa, MG. 150p. (Manual do Usuário).

VAN SOEST, P.J. 1994. Nutritional ecology of the ruminant. Ithaca: Comstock Publ. Assoc. 476p.

WEINBERG, Z.G. Bioconservation of agricultural by-products by ensiling In: SIMPÓSIO UTILIZAÇÃO DE SUBPRODUTOS AGRO-INDUSTRIAIS E RESÍDUOS DE COLHEITA NA ALIMENTAÇÃO DE RUMINANTES, 1992 São Carlos, SP. Anais...São Carlos: EMBRAPA/UEPAE. 1992. p.191-197.

Recebido em: 29/09/1999

Aceito em: 12/05/2000 